How does the economic risk aversion affect biodiversity?

\author{
Lauriane MOUYSSET \\ CERSP, UMR 7204, CNRS-MNHN-UPMC \\ SADAPT, INRA, UMR 1048 \\ LUC DOYEN \\ CERSP, UMR 7204, CNRS-MNHN-UPMC \\ GREThA, CNRS, UMR 5113 \\ Université de Bordeaux \\ Fréderic JIGUET \\ CERSP, UMR 7204, CNRS-MNHN-UPMC
}

Cahiers du GREThA

$n^{\circ}$ 2012-03

January

\author{
GRETHA UMR CNRS 5113 \\ Université Montesquieu Bordeaux IV \\ Avenue Léon Duguit - 33608 PESSAC - FRANCE \\ Tel : +33 (0)5.56.84.25.75 - Fax : +33 (0)5.56.84.86.47 - www.gretha.fr
}


Comment l'aversion au risque économique favorise la biodiversité ?

\title{
Résumé
}

L'article analyse le rôle joué par l'aversion au risque dans la réconciliation entre l'agriculture et la biodiversité. Est développé un modèle bio-économique qui articule à une échelle micro la dynamique de communauté d'oiseaux et la dynamique d'agents représentatifs sélectionnant leurs occupations des sols agricoles dans un environnement incertain. Le modèle est spatialisé et calibré à l'échelle régionale (petites régions agricoles) pour la France métropolitaine à partir de séries temporelles nationales 2001-2009. L'impact de l'aversion au risque est évalué sur les performances à la fois économiques, agricoles et écologiques à travers des projections à l'horizon 2050. Une aversion assez élevée s'avère suffisante pour l'obtention de performances bio-économiques satisfaisantes à l'échelle macro et pour promouvoir ainsi une agriculture multi-fonctionnelle. Cela se produit à travers un mécanisme de diversification sur les utilisations de terre. Les disparités spatiales suggèrent que les incitations publiques pourraient être nécessaires pour renforcer la diversification et l'efficacité bio-économique.

Mots-clés : Biodiversité, agriculture, bio-économie, modélisation, aversion au risque, oiseaux, diversification.

\section{How does the economic risk aversion affect biodiversity?}

\begin{abstract}
The present paper analyses the role played by risk aversion in the reconciling of agricultural income and biodiversity. A bio-economic mode which articulates bird community dynamics and representative farmers selecting land uses within an uncertain macro-economic context is developed. It is spatialized and calibrated at a regional scale for France through national databases. The impact of risk aversion is assessed on economic, agricultural and ecological outputs through projections at the 2050 horizon. A high enough aversion proves sufficient to promote global bio-economic performance and multi-functional agriculture. This occurs through a diversification mechanism on regional land-uses. Spatial disparities however suggest that public incentives could be necessary to reinforce the diversification and bioeconomic effectiveness.
\end{abstract}

Keywords: Agriculture, Aversion, Bio-economic modeling, Bird, Biodiversity, Diversification, Public good, Spatial

JEL: Q15, Q20

Reference to this paper: MOUYSSET Lauriane, DOYEN LUC, JIGUET Frédéric (2012) How does the economic risk aversion affect biodiversity?, Cahiers du GREThA, $\mathrm{n}^{\circ} 2012-03$.

http://ideas.repec.org/p/grt/wpegrt/2012-03.html. 


\section{Introduction}

Significant decline of biodiversity in European farmlands has been reported for several decades. Numerous studies point out spatial and temporal correlations between farmland biodiversity and agricultural changes (Donald et al., 2001 and 2006; Wretenberg et al.,2007; Chamberlain et al., 2000). Modern agriculture and associated intensification of practices have been identified as major drivers of this erosion in farmland biodiversity. The breeding bird populations are particularly vulnerable to global agricultural change (Chamberlain et al., 2000, Jiguet et al., 2010a, Krebs et al., 1999). Such a negative effect is due mainly to a degradation in habitat quality altering nesting success and survival (Benton et al., 2003). In this context, the European Union has formally adopted the Farmland Bird Index (FBI) as an indicator of structural changes in biodiversity (Balmford et al., 2005).

A challenge to reach sustainability for agricultural land-use is therefore to reconcile farming production and farmland biodiversity. Usual approaches to achieve such multifunctional goals for farming rely on public policies (Pacini et al., 2004) or economic incentives (Dreschler et al., 2007; Mouysset et al., 2011). For Alavalapati et al. (2002) and Shi et al. (2005), financial incentives are essential to convincing farmers to adopt eco-friendly activities. These policies modify the farmer's choices and thus impact both the habitat and the dynamics of biodiversity (Doherty et al., 1999, Holzkmper et al., 2007, Rashford et al., 2008). In this perspective, many public policies including agri-environmental schemes have been developed by decision makers. However, fifteen years after the initial implementation of such instruments at a large scale, their ability to enhance biodiversity remains controversial (Butler et al., 2007, Kleijn et al., 2006, Vickery et al., 2004). In this context, other levers can be investigated to promote sustainable agriculture. In particular, some studies focus on the farmer's microeconomic features, threating them as forms of risk aversion (Lein, 2002, Hardacker, 2000). Hence theoretical models (Quaas et al., 2007) suggest that an adequate risk aversion may bring farmers to adopt choices which favor biodiversity. The underlying mechanism is that risk averse farmers maintain an important agrobiodiversity in their farming system as a way of managing increasing environmental risk (Baumgartner et al., 2010). Furthermore, strong agrobiodiversity also has a positive impact on farmland biodiversity (Laiolo et al., 2005, Robinson et al., 2001).

The objective of this work is to analyze to what extent risk aversion promotes the reconciliation between agricultural income and farming biodiversity. For this purpose, a bio-economic dynamic model is developed for metropolitan France spatialized at the regional scale. By comparing the role played by the degrees of farmer risk aversion on bio-economic outcomes, it aims at quantifying the impact of economic aversion on the agro-ecosystem for both private (income) and public (farmland birds) goods.

To address such agro-environmental issues, different bio-economic modeling frameworks are proposed in the literature. Cost-Benefit methods require quantification of biodiversity in monetary terms (Dreschler 2001, Rashford et al., 
2008). Although pricing techniques such as contingent valuation are available, their suitability for the complex issues of biodiversity is disputed, notably in anthropogenic systems (Diamond et al. 1994). In this context, cost-effectiveness is an interesting alternative to avoid monetary evaluation of environmental goods (Gato and De Leo, 2000). Approaches such as ecological economics suggest studying environmental and economic performances simultaneously, stressing the relevance of multi-criteria approaches (Dreschler et al., 2007, Mouysset et al., 2011). However the metrics to adopt for evaluating biodiversity are not self-apparent and indicators used to assess biodiversity and environmental services are highly diverse (Havlik et al., 2005, Van Wenum et al., 2004, Polasky et al., 2003). Moreover, numerous models emphasize spatial dimensions in dealing with agro-ecological issues. Such spatially explicit models aim at assessing consequences of different land use patterns for various environmental and economic criteria (Irwin and Geoghegan, 2001; Swihart et al., 2003; Polasky et al., 2003; Groot et al., 2007). Nevertheless, most of these models are static, restricting the potential ecological processes accounted for. In the same vein, most of these models are deterministic and do not take into account the various uncertainties involved in the ecological and economic processes at play.

The bio-economic model proposed in this article is in direct line with these considerations. The model integrates representative rational agents selecting farming land-uses in an uncertain economic context through some expected utility and bird community dynamics driven by these land uses. The model is thus dynamic. Furthermore, it articulates ecological and economic compartments and adopts a multi-criteria perspective. Moreover, it offers a spatialized perspective as it is built up at a macro-regional scale and its calibration relies on French regional data of both land-use and bird abundance. Biodiversity is measured through the European Farmland Bird Index (FBI) which has already shown its relevance to reflect the response of farmland biodiversity to intensification of agriculture (Doxa et al., 2010; Mouysset et al., 2011). Moreover, the model accounts for economic uncertainties through gross margins. In this context, different projections and scenarios at the 2050 horizon give insights into the positive influence of economic risk aversion for reconciling agricultural income and biodiversity. It is shown how such multi-functionality is related to the heterogeneity of farming habitats and land-uses.

The paper is organized as follows. The second section describes the spatialized dynamic model and the bio-economic indicators. The third section presents the results regarding the influence of risk aversion on bio-economic performances. The fourth section is devoted to the discussion of these results.

\section{Material and method}

\subsection{Context and data}

Metropolitan France is split into 620 small agricultural regions (PRA for Petites Regions Agricoles). A PRA is part of a department (a major French administrative entity) which exhibits an agro-ecological homogeneity. This consistency from both the ecological and economic points of view makes the PRA 
scale well suited for our bio-economic modeling. The model described below is built for each PRA.

To assess the ecological performance, we here choose to focus on common bird populations and related indicators (Gregory et al., 2009). Although the metric and the characterization of biodiversity remain an open debate (MEA 2005), such a choice is justified for several reasons (Ormerod et al., 2000): (i) Birds lie at a high level in the trophic food chains and thus capture the variations in the chains. (ii) Birds provide many ecological services, such as the regulation of rodent populations and pest control, thus justifying our interest in their conservation and viability (Sekercioglu et al., 2004). (iii) Their close vicinity to humans makes them a simple and comprehensive example of biodiversity for a large audience of citizens.

The STOC (French Bird Breeding Survey) database ${ }^{1}$ provided the informations related to the bird abundances across the whole country. Abundance values for each species were available for the period 2001-2008 for 1747 squares (a square is $2 * 2 \mathrm{~km}^{2}$ in size). For each species, we further performed a spatial interpolation of these abundance data to obtain relative abundance values for each possible square in the country (e.g. 136000 squares) using kriging models based on spatial autocorrelation and the exponential function (Doxa et al., in press). We then averaged the abundance values at the PRA scale. Among the species monitored by this large-scale long-term survey, we selected 20 species which have been classified as farmland specialists according to their habitat requirements at a Europe scale (EBCC, 2007). Appendix 1 lists the 20 species used as a reference for the European Farmland Bird Index FBI (Gregory et al., 2009). Previous analyses have shown the relevance of the national FBI to reflect the response of farmland biodiversity to agricultural intensification (Doxa et al., in press).

For agro-economic data, we use the French agro-economic classification OTEX (orientation technico-economique) developed by the French Farm Accounting Data Network $(F A D N)^{2}$ and the Observatory of Rural Development (ODR $)^{3}$. This organization distinguishes 14 classes of OTEX (see appendix B). Each PRA is a specific combination of these OTEX. The surfaces dedicated to each of the 14 OTEX and the associated gross margins, for the years 2001 to 2008 are available on the ODR website under a private request. Gross margin is an economic index broadly used in agricultural economics (for instance Lein et al., 2002) and bio-economic modeling (ten Berge et al., 2000, Pacini et al., 2004).

\subsection{The ecological model}

Regarding bird populations, we chose a dynamic framework. We here adopt the Beverton-Holt model (Beverton and Holt, 1957) which accounts for the

\footnotetext{
${ }^{1}$ See the Vigie-Nature website http://www2.mnhn.fr/vigie-nature/. Standardized monitoring of spring-breeding birds at $17472 * 2 \mathrm{~km}^{2}$ plots across the whole country. Details of the monitoring method and sampling design can be found in Jiguet et al. (2010b).

${ }^{2}$ http://ec.europa.eu/agriculture/rica/

${ }^{3}$ https://esrcarto.supagro.inra.fr/intranet/
} 
intra-specific competition and the density dependence as follows:

$$
N_{s, r}(t+1)=N_{s, r}(t) \cdot \frac{1+R_{s, r}}{1+\frac{N_{s, r}(t)}{M_{s, r}(t)}}
$$

where $N_{s, r}(t)$ stands for the bird abundance of species $s$ in a PRA $r$ at year $t$. The $R_{s, r}$ coefficient corresponds to the intrinsic growth rate specific to each species $s$. This parameter takes into account the characteristics of each species such as clutch size, mean reproductive success, or number of clutches per year. The product $M_{s, r}(t) * R_{s}$ represents the carrying capacity of the habitat $r$ and the value $M_{s, r}$ captures the ability of the habitat to host the species.

Habitat index $M_{s, r}(t)$ is assumed to depend linearly on OTEX as follows:

$$
M_{s, r}(t)=b_{s, r}+\sum_{k} a_{s, r, k} \cdot A_{r, k}(t)
$$

where $A_{r, k}(t)$ represents the share of the PRA $r$ dedicated to OTEX $k$ at time $t$. The $a_{s, r, k}$ and $b_{s, r}$ coefficients, specific to each species, quantify how the species $s$ responds to the various OTEX $k$ in a given region $r$. The $b_{s, r}$ coefficient can be interpreted as the mean habitat coefficient for a species $s$ in a PRA $r$.

To estimate these different parameters, we use a least square method to minimize errors between the observed abundances $N_{s, r}$ as issued from STOC and the values derived from the model $\widehat{N}_{s, r}$ :

$$
\min _{R, a, b} \sum_{s, r, t}\left(N_{s, r}(t)-\widehat{N}_{s, r}(t)\right)^{2}
$$

Figure 1 illustrates the results of this calibration for national abundances of two species: the Stonechat Saxicola torquatus and the Red-backed Shrike Lanius collurio. More globally, the errors of estimation per PRA are about $0.08 \%$. Comparing the historical abundances with the model-generated ones, we note that the model tends to smooth the variations of the observed data.

\subsection{The economic model of the farmer}

Each PRA $r$ is assumed to be managed by a representative farmer who selects land-uses (OTEX) along time. The farmer determines the surfaces $A_{r, k}(t)$ of each OTEX $k$ in a PRA $r$ in order to maximize some expected utility depending on mean and dispersion of incomes together with risk aversion. The income $\operatorname{Inc}_{r}(t)$ is the sum of the incomes generated by the agricultural activities $k$ through the unit gross margins $\operatorname{gm}_{r, k}(t)$ :

$$
\operatorname{Inc}_{r}(t)=\sum_{k} \operatorname{gm}_{r, k}(t) \cdot A_{r, k}(t)
$$

Gross margins $\operatorname{gm}_{r, k}(t)$ are supposed to be uncertain. The variability on gross margins includes both market, production and climate uncertainties. A 
Gaussian distribution parametrized with the mean and the covariance matrix of the historical data is chosen to capture such uncertainties. Also assumed is a quadratic form for the utility function of the representative agent (Lein, 2002). Hence, the utility $U_{r}(t)$ for the representative farmer corresponds to the difference between an expected income $\mathbb{E}\left[\operatorname{Inc}_{r}(t)\right]$ and its risky part $\operatorname{Var}\left[\operatorname{Inc}_{r}(t)\right]$ :

$$
\begin{aligned}
U_{r}(t) & =\mathbb{E}\left[\operatorname{Inc}_{r}(t)\right]-a \cdot \operatorname{Var}\left[\operatorname{Inc}_{r}(t)\right] \\
& =\sum_{k} \overline{\operatorname{gm}}_{r, k} \cdot A_{r, k}(t)-a \cdot \sum_{k} \sum_{k^{\prime}} \sigma_{r, k, k^{\prime}}(t) \cdot A_{r, k}(t) \cdot A_{r, k^{\prime}}(t)
\end{aligned}
$$

Expected gross margins $\overline{\mathrm{gm}}_{r, k}$ are the mean of the 7 historical years ${ }^{4}$. The coefficient $a$ represents the risk aversion level of the farmer: the higher the $a$, more risk-averse the farmer. In particular $a=0$ means farmers are risk neutral, they make their choices only focusing on the expected income. The risky term is computed with the covariance ${ }^{5} \sigma_{r, k, k^{\prime}}$ between margins of land-uses $k$ and $k^{\prime}$ in region $r$. The maximizing program of farmer's utility in an uncertain context is defined as follows:

$$
\max _{A_{r, 1}, \ldots, A_{r, 14}} U_{r}(t)
$$

However when maximizing the utility, the standard agent must comply with two constraints at every point in time:

$$
\begin{gathered}
\left|A_{r, k}(t)-A_{r, k}(t-1)\right| \leq \varepsilon \cdot A_{r, k}(t-1) \\
\sum_{k} A_{r, k}(t)=A_{r}
\end{gathered}
$$

The first constraint (eq. 8) corresponds to a technical constraint where the coefficient $\varepsilon$ stands for the rigidity in changes. For example, the case where $\varepsilon=0$ means that the land uses remain constant. The second constraint (eq. 9) merely ensures that the total agricultural surface $A_{r}$ per PRA remains constant. Typically, forest and urban areas are assumed to be fixed.

\subsection{Projections and indicators}

Ecological and economic models described previously are thus linked through the agricultural system's OTEX as depicted by figure 2. With the objective of maximizing incomes under technical and inertia constraints, the representative farmer in each PRA selects a pattern of OTEX $A_{r, k}(t)$ which impacts the ecological dynamics through the habitat $M_{s, r}(t)$. The farming land-uses are outputs of the economic model and inputs of the ecological model. The economic choices thus condition bird abundances $N_{s, r}(t)$ associated with the habitats.

$$
\begin{aligned}
& { }^{4} \overline{\mathrm{gm}}_{r, k}=\frac{1}{7} \sum_{t=1}^{t=7} \operatorname{gm}_{r, k}(t) . \\
& { }^{5} \sigma_{r, k, k^{\prime}}=\frac{1}{7} \sum_{t=1}^{t=7}\left(\operatorname{gm}_{r, k}(t)-\overline{\operatorname{gm}}_{r, k}(t)\right) \cdot\left(g m_{r, k^{\prime}}(t)-\overline{\operatorname{gm}}_{r, k^{\prime}}(t)\right) .
\end{aligned}
$$


We made different projections to analyze possible future trends of agriculture and biodiversity according to risk aversion of farmers involved in utility defined in (6). We test eight risk aversion levels $a$ between $10^{-4}$ and $10^{-8}$ as suggested by Lein (2002). For the projections, we do not add public policies compared to the current situation in contrast with Mouysset et al. (2011). In other words, the case studied here corresponds to a Statu Quo scenario in the sense that it is assumed that the farmers evolve under the current policy context. The selected time frame runs from 2009 to 2050, i.e a 42-year forecast. Selecting a shorter time frame could consequently hide interesting long-term effects due to the inertia of the models.

To analyze bio-economic performances, we focus on both economic, land-uses and ecological performances at national and regional scales.

\subsection{Economic index}

From an economic viewpoint, we use the regional income per income $\operatorname{Inc}_{r}(t)$ defined in equation (4) and the national mean income per hectare $\overline{\operatorname{Inc}}_{\text {nat }}(t)$ defined in eq. (10). The national income is computed from the mean gross margin of the $620 \mathrm{PRA}$ :

$$
\overline{\operatorname{Inc}}_{\text {nat }}(t)=\frac{1}{A_{\text {nat }}} \sum_{r=1}^{620} A_{r} \cdot \operatorname{Inc}_{r}(t)
$$

where $A_{\text {nat }}=\sum_{r=1}^{620} A_{r}$ is the total surface of PRA over France. For sake of clarity, we will represent this criterion on figures 3 and 4 after a normalization by their current value (2008).

\subsection{Biodiversity index}

From an ecological viewpoint, we have selected the Farmland Bird Index (FBI). We focus on this indicator which has been adopted by the European Community as the official environmental index especially to analyze structural changes in biodiversity (Balmford et al., 2005). FBI is an index of variation in abundances here computed with respect to the reference year 2008 . We first estimated a regional FBI with 20 farmland specialist species (Appendix A) for each PRA $r$ as follows:

$$
\mathrm{FBI}_{r}(t)=\prod_{s \in \text { Specialist }}\left(\frac{N_{s, r}(t)}{N_{s, r}(2008)}\right)^{1 / 20}
$$

Then at the national scale for France, we considered the aggregated indicator $\mathrm{FBI}_{\text {nat }}$

$$
\mathrm{FBI}_{\text {nat }}(t)=\prod_{s \in \text { Specialist }}\left(\frac{N_{s, \text { nat }}(t)}{N_{s, \text { nat }}(2008)}\right)^{1 / 20}
$$

where $N_{s, \text { nat }}(t)$ stands for the total abundance of species $s$ over all PRA $r$. 


\subsection{Habitat heterogeneity index}

To analyze farming and habitat heterogeneity, we use an agricultural diversification indicator denoted by $\operatorname{Hdiv}_{r}(t)$. It is here computed as the Simpson Index of land-uses $A_{r, k}(t)$ :

$$
\operatorname{Hdiv}_{r}(t)=\left(\sum_{k=1}^{14}\left(\frac{A_{r, k}(t)}{A_{r}(t)}\right)^{2}\right)^{-1}
$$

This indicator evaluates the bias compared to the equi-distribution. Its maximum is achieved when the agricultural area is divided equally between the 14 OTEX.

We also estimate an average heterogeneity indicator over France $\operatorname{Hdiv}_{\text {nat }}(t)$ as an arithmetic mean of the 620 indicators at the PRA scale:

$$
\operatorname{Hdiv}_{\text {nat }}(t)=\frac{1}{620} \sum_{r=1}^{620} \operatorname{Hdiv}_{r}(t)
$$

\section{Results}

As the modeling is realized in an uncertain context, we run one hundred simulations with different random Gaussian gross margins $\operatorname{gm}_{r, k}(t)$. Then both at PRA and national scales, we compute at any time the mean of the simulations for economic, ecological and farming diversification indicators $\operatorname{Inc}(t), \operatorname{FBI}(t)$ and $\operatorname{Hdiv}(t)$ along with their $95 \%$ confident interval.

\subsection{Bioeconomic performances depending on risk aversion}

We first compare the bio-economic performances for various levels of risk aversion at the national scale. Figure 3 represents the mean of the 100 runs for different risk aversion $a$. We observe a set of contrasted trajectories: Those with strong risk aversion levels are beneficial to the biodiversity while those with weak risk aversion levels promote the economic indicator. In other words, the risk aversion plays a significant role in the bio-economic performances achieved along time. However the ecological and economic performances are inversely correlated and thus different trade-offs can occur: there is no path optimizing both the economic and the biodiversity criteria.

\subsection{Performances and volatilities}

Figure 4 compares the national bio-economic performances and agricultural diversification by displaying the means with $95 \%$ confident interval for three contrasted levels of risk aversion $a$. We observe a positive correlation between FBI and agricultural diversification. This is clearly confirmed by a statistical analysis $\left(R 2=57 \%, \mathrm{P}\right.$-value $\left.\leq 2.2 e^{-16}\right)$ : positive ecological performances are associated to a strong national OTEX diversification.

Concerning the dispersion of the outputs, the national income is the most stongly affected indicator. The poorest risk aversion allows for a better growth 
of national income in the mean but with the largest deviation. By contrast, with the strongest risk aversion, the national income is just stabilized but the volatility is practically null. The intermediate risk aversion leads to a moderate income growth with little volatility. On the ecological side, we note that economic risk aversion does not strongly affect the volatility of farmland bird indicators. The standard deviation is about $3 \%$ for all cases. Similarly the agricultural diversification dispersion is not deeply impacted by risk aversion as it ranges from $2 \%$ to $3 \%$.

\subsection{Performances at the PRA scale}

Figure 5 displays the habitat diversification indicator $\operatorname{Hdiv}_{r}(t)$ at the PRA scale in $2008(\mathrm{t}=0)$ and in 2050, with three contrasted risk strategies. Risk aversion plays the same role qualitatively for the broad majority of regions. With a strong risk aversion, a habitat heterogeneity occurs. Conversely, with a weak risk aversion, we observe a specialization for most regions: the heterogeneity index decreases in comparison with 2008.

Figure 6 compares the $\mathrm{FBI}_{r}$ at the PRA scale in 2008 and in 2050 for the three risk aversion levels $a$. It turns out that the effect of risk aversion on ecological performances at the PRA scale is more reduced than on the agricultural heterogeneity. We observe a global enhancement of regional FBI for the strongest risk aversion levels. Still, contrary to the agricultural diversification maps of figure 5, figure 6 captures many regional disparities: some PRA have a significant FBI improvement and others exhibit a steady FBI.

Statistical analysis strongly emphasizes significant correlations between OTEX diversification and FBI for all PRA (P-value $\leq 2.2 \mathrm{e}-16)$. Nevertheless the quality of the fitness varies among the PRA: R2 varies between $3 \%$ and $94 \%$, with a mean at $20 \%$.

Finally, figure 7 compares the mean income $\operatorname{Inc}_{r}(t)$ at the PRA scale in 2008 and in 2050 for the three risk aversions. Although risk aversion globally lessens the incomes, many regional discrepancies emerge similarly to bird biodiversity.

\section{Discussion}

\subsection{Spatio-temporal bio-economic models to manage biodiversity}

This paper presents an inter-disciplinary approach which is needed (Perrings et al., 2006, DeLara \& Doyen, 2008) to operationalize a sustainable management of biodiversity and agriculture. Despite divergences between economic and ecological disciplines (Dreschler, 2007b), our model couples economic and ecological dynamics to analyze bio-economic performances of French agriculture at the national scale. This approach avoids the biodiversity monetary evaluation which is controversial (Rees, 1998). The coupling of economic (gross margins), agronomical (land uses) and ecological (bird abundances) data gives strong realism to the modeling. The precision to integrate these data compensates for the simple formalism of the model and makes it possible to obtain robust and informative results. With the integration of regional economic and ecological 
specificities, the model is spatialized, which reinforces its relevance (Polasky et al., 2003). Taking account of economic uncertainties through gross margins also reinforces its credibility. The choice to focus on a bird taxa rather than one or two emblematic species makes it possible to obtain more general results regarding biodiversity. Finally, the dynamic aspect which allows an adjustment of the carrying capacity function of land uses leads to a precise representation of impact of land uses on avifauna evolution and transient dynamics. The integration of these uncertain spatio-temporal components, multi-scale data and the multi-criteria viewpoint creates a flexible modeling framework allowing many developments and refinements.

\subsection{Economic risk aversion to promote biodiversity performances}

This study suggests that biodiversity management and conservation is achievable through economic risk aversion. This aversion is sufficient for the farmers to select their land uses in an eco-friendly manner. Consequently the result presented here, based on utility maximization without any ecological awareness or goals, has sound connections with the theoretical statement of Quaas and al. (2007): farmers do not necessarily need to have environmental preferences or to receive monetary benefits from ecosystem services to favor a land-use strategy allowing for a sustainable path for biodiversity. Hence, risk aversion can be a major driver of the multi-functional agriculture and its impact seems strong enough to promote satisfying ecological performances and stop biodiversity erosion. In this respect, it would be interesting to add incentives scenarios into this model to show how public policies can reinforce such bio-economic outcomes and scenarios as in Mouysset et al. (2011).

\subsection{Agricultural diversification to reconcile private and public goods}

This study also suggests that a conciliation between biodiversity and agricultural objectives is feasible through diversification and risk aversion. As mentioned by Baumgartner and Quaas (2010), risk-averse farmers choose agricultural diversification to manage their economic risk. Risk-averse farmers diversify their agricultural activities in order to mitigate the uncertainties on expected incomes as in the portfolio theory for financial issues (DiFalco et al., 2007, DiFalco and Perrings, 2003, Schlapfer et al., 2002). With these insurance effects, the diversification has a positive effect on private goods. However, the previous paragraph points out that this diversification also has a strong positive impact on the production of public goods. Indeed, agricultural diversification creates heterogeneity of habitats and available resources which are essential for birds as stressed by Benton and al. (2003). This positive effect of diversification on biodiversity has been experimentally and separately identified for different land uses in Laiolo (2005) and for crop landscapes and grasslands in Robinson et al. (2001). A strong risk-averse behavior leads to a simultaneous diversity, which improves the dynamics of bird communities. Land use heterogenity induced by risk-averse farmers thus seems an efficient way of promoting both private and public values. 
More globally, farming diversification is positive for the functioning of the agro-ecosystem. According to the insurance hypothesis (Yachi et Loreau 1999), an increasing biodiversity insures ecosystems against declines in their functioning caused by environmental fluctuations. Such an effect is expected because different species can adapt differently to environmental changes (Doak et al., 1998; Ives et al., 1999). Communities with strong biodiversity are more stable and more productive in the ecological sense than those with poor biological diversity (Caldeira et al., 2005). Hence, agricultural and habitat diversity acts as a public natural insurance. Moreover, a larger and more diverse community provides the agrosystems with various ecosystem services such as pest control, pollination and decomposition processes (Altieri 1999, Schlapfer et al., 1999; Tilman et al., 2002, Wildy and Thomas, 2002) and consequently induces a stronger ecosystem viability. These services should indirectly contribute to the farming production and to its sustainability. In this context, agricultural diversification developped by risk-averse farmers could itself be identified as an ecosystem service yielding both private and public insurance effects for the agro-ecosystem.

\subsection{Regional disparities}

Finally the spatial distribution of performances shows that trends at the national scale hide many disparities between PRA. Economic risk aversion is sufficient to promote biodiversity at the national scale, but it is not enough for every PRA. Hence, some regions which enhance agricultural heterogeneity in a context of strong risk aversion do not always exhibit a strong FBI. This result suggests that other mechanisms govern bird dynamics. In particular, the quality of this diversification could be important: some agricultural systems such as extensive farming are decisive for specific bird populations. In this context, public policies could be developed to favor some agricultural systems and reinforce the diversification mechanisms mentioned above. Strong income differences between PRA are also in favor of public policies to reduce economic disparities. Alavalapati et al. (2002), Shi et al. (2005) and Mouysset et al. (2011) have shown the effectiveness of some public policies for both ecological and economic criteria. In a regional perspective, the public policies seem to be essential to manage biodiversity and mitigate economic regional differences.

\section{Conclusion}

We conclude that risk aversion directly leads to an agricultural diversification which has strong positive impacts for the agro-ecosystem. This diversification plays on private goods by mitigating income volatility and by promoting numerous and stable ecosystem services which can be used by the farmers. From the ecological point of view, it promotes public goods production through broader and stabilized farmland bird communities. However, the effect of this risk aversion differs among the PRA. The public incentives appear essential to drive this diversification in order to reduce both ecological and economic disparities. To enhance their effectiveness, such policies should account for risk aversion to foster spontaneous diversification. 


\section{Acknowledgements}

This work was carried out with the financial support of the "ANR - Agence Nationale de la Recherche- The french National Research Agency" under the "Systerra program - Ecosystems and Sustainable Development," project "ANR08-STRA-007,FARMBIRD-Coviabilty models of Farming and Bird biodiversity." Such studies would not be feasible without the dedicated help of hundreds of volunteers monitoring the bird communities across the country very year.

\section{Appendices}

\section{A. 20 farmland bird species $s$}

(1) Buzzard Buteo buteo, (2) Cirl Bunting Emberiza cirlus, (3) Corn Bunting Emberiza calandra, (4) Grey Partridge Perdix perdix, (5) Hoopoe Upupa epops, (6) Kestrel Falco tinnunculus, (7) Lapwing Vanellus vanellus, (8) Linnet Carduelis cannabina, (9) Meadow Pipit Anthus pratensis, (10) Quail Coturnix coturnix (11) Red-backed Shrike Lanius collurio, (12) Red-legged Partridge Alectoris rufa, (13) Rook Corvus frugilegus, (14) Skylark Alauda arvensis, (15) Stonechat Saxicola torquatus, (16) Whinchat Saxicola rubetra, (17) Whitethroat Sylvia communis, (18) Wood Lark Lullula arborea, (19) Yellowhammer Emberiza citrinella, (20) Yellow Wagtail Motacilla flava.

\section{B. 14 agricultural systems (Otex) $k$}

(1) Cereal, Oleaginous, Proteaginous (COP) ; (2) Variegated crops ; (3) Intensive bovine livestock breeding ; (4) Medium bovine livestock breeding ; (5) Extensive bovine livestock breeding ; (6) Other herbivorous livestock breeding ; (7) Mixed crop-livestock farming with herbivorous direction ; (8) Mixed crop-livestock with granivorous direction ; (11) Mixed crop-livestock with other direction ; (10) Granivorous livestock breeding ; (11) Permanent farming ; (12) Flower farming ; (13) Viticulture ; (14) Others.

\section{References}

Alavalapati, J.R.R., Stainback, G.A., Carter, D.R., (2002) Restoration of the longleaf pine ecosystem on private lands in the US South: an ecological economic analysis. Ecol Econ 40:411-419.

Altieri, M.A. (1999) The ecological role of biodiversity in agroecosystems. Agric Ecosyst Environ 74:19-31.

Balmford, A., Bennun, L., Brink, B. ten, et al. (2005) The Convention on Biological Diversity's 2010 Target. Science 307:212 - 213.

Baumgartner, S. and Quaas, M.F. (2010) managing increasing environmental risks through agrobiodiversity and agrienvironmental policies. Agric Econ, 41, 483-496. 
Benton, T.G, Vickery, J.A. and Wilson, J.D. (2003) Farmland biodiversity: is habitat heterogeneity the key? Trends Ecol Evol 18:182-188.

Berge ten, H.F.M., Ittersum van, M.K., Rossing, W.A.H, et al. (2000) Farming option for the Netherlands explored by multi-objective modelling. Eur J Agron 13:263-277.

Beverton, R.J.H. and Holt, S.J. (1957) On the Dynamics of Exploited Fish Populations, Fishery Investigations, II, Ministry of Agriculture, Fisheries and Food.

Butler, S.J., Vickery, J. A., Norris, K. (2007) Farmland Biodiversity and the Footprint of Agriculture. Science 315:381 - 384.

Caldeira, M.C., Hector, A., Loreau, M. et al. (2005) Species richness, temporal variability and resistance of biomass production in a Mediterranean grassland. Oikos, 110:115-123.

Chamberlain, D.E., Fuller, R.J., Bunges, R.G.H., Duckworth, J.C. and Shrubb, M. (2000) Changes in the abundance of farmland birds in relation to the timing of agricultural intensification in England and Wales. J Appl Ecol 37:771-788.

De Lara M. and Doyen L. (2008) Sustainable Management of Natural Resources. Mathematical Models and Methods. Springer-Verlag, Berlin.

Diamond, P.A. and Hausman, J.A. (1994) Contingent valuation: Is some number better than no number? J Econ Perspectives 8:45-64.

Di Falco, S. and Perrings, C. (2005) Crop biodiversity, risk management and the implications of agricultural assistance. Ecol Econ 55:459-466.

Di Falco, S., Chavas, J-P. and Smale, M. (2007) Farmer management of production risk on degraded lands: the role of wheat variety diversity in the Tigray region, Ethiopia. Agric Econ 36:147-156.

Dreschler, M. and Watzold, F. (2001) The importance of economic costs in the development of guidelines for spatial conservation management. Biol Conserv 97:51-59.

Dreschler, M. and Wtzold, F. (2007) Ecological-economic modeling for the sustainable use and conservation of biodiversity. Ecol Econ 62:203-206.

Doak, D.F., Bigger, D, Harding, E.K., et al. (1998) The statistical inevitability of stability-diversity relationship in community ecology. The American Naturalist 151:264-276.

Doherty, P.F., Marschall, E.A. and Grubb, T.C.Jr (1999) Balancing conservation and economic gain: a dynamic programming approach. Ecol Econ 29:349-358.

Donald, P.F., Green, R.E. and Health, M.F. (2001) Agricultural intensification and the collapse of Europe's farmland bird populations. Proc R Soc Lond, B, Biol Sci 268:25-29.

Donald, P.F., Sanderson, F.J., Burfield, I.J. and van Bommel, F.P.J. (2006) Further evidence of continent-wide impacts of agricultural intensification on European farmland birds, 1990-2000. Agric Ecosyst Environ 116:189-196.

Doxa, A., Bas, Y., Parracchini, M.L., Pointereau, P., Terres, J-M. and Jiguet, F. (2010 in press) Low-intensity agriculture increases farmland bird abundances in France. J Appl Ecol. doi: 10.1111/j.1365-2664.2010.01869.x 
European Bird Census Council, (2007) The state of Europe's Common Birds. Ed EBCC.

Gatto, M. and De Leo, (2000) Pricing biodiversity and ecosystem services: the never ending story. Bioscience, 50: 347-355.

Gregory, R.D., Willis, S.G., Jiguet, F., et al. (2009) An indicator of the impact of climate change on European bird populations. PloS ONE 4(3): e4678. doi:10.1371/journal.pone.0004678

Groot, J.C.J., W.A.H. Rossing, A. Jellema, D.J. Stobbelaar, H. Renting, and M.K. Van Ittersum 2007. Exploring multi-scale trade-offs between nature conservation, agricultural profits and landscape quality - a methodology to support discussions on land-use perspectives. Agric Ecosyst Environ 120:58-69.

Hardacker, J.B. (2000) Some issues in dealing with risk in agriculture. Working Paper in Agricultural and Resource Economics. Scool of Economics Studies, University of New England, Armidale.

Havlk, P., Veysset, P., Boisson, J.M., Lherm, M. and Jacquet, F. (2005) Joint production under uncertainty and multi functionality of agriculture: policy considerations and applied analysis. European Review of Agric Econ 32:489515 .

Holzkamper, A. and Seppelt, R. (2007) Evaluating cost-effectiveness of conservation management actions in an agricultural landscape on a regional scale. Biol Conserv 136:117-127.

Irwin, E.G. and Geoghegan, J. (2001) Theory, data, methods: developing spatially explicit economic models of land use change. Agric Ecosyst Environ 85:7-23.

Ives, A.R., Gross, K. and Klug, J.L. (1999) Stability and variability in competitive communities. Science 286:542-544.

Jiguet, F. (2009) Method-learning caused first-time observer effect in a newly-started breeding bird survey. Bird Study, 56:253-258. doi:10.1080/00063650902791991

Jiguet, F., Gregory, RD., Devictor, V., et al. (2010a). Population trends of European birds are correlated with characteristics of their climatic niche. Global Change Biology 16, 497-505. doi:10.1111/j.1365-2486.2009.01963.x

Jiguet, F., Devictor, V., Ottvall, R., et al. (2010b) Bird population trends are linearly affected by climate change along species thermal ranges. Proc $\mathrm{R}$ Soc Lond, B, Biol Sci 277:3601-3608. doi:10.1098/rspb.2010.0796

Kleijn, R. A., Baquero, Y., Clough, M., et al. (2006) Mixed biodiversity benefits of agri-environment schemes in five European countries, Ecol Lett 9:243254 .

Krebs, J.R., Wilson, J.D., Bradbury, R.B. and Siriwardena, G.M. (1999) The second silent spring? Nature, 400, 611-612.

Laiolo P. (2005) Spatial and seasonal patterns of bird communities in Italian agroecosystems. Conserv Biol 19:1547-1556.

Lien, G. (2002) Non-parametric estimation of decision makers' risk aversion. Agric Econ 27:75-83.

Millennium Ecosystem Assessment, (2005). Ecosystems and human well being: current state and trends. Chapter 26 : cultivated systems. Island Press, Washington, pp 745-794. 
Mouysset, L., Doyen, L., Jiguet, F., et al. (2011) Bio economic modeling for a sustainable management of biodiversity in agricultural lands. Ecol Econ. 70, 617-626.

Ormerod, S.J. and Watkinson, A.R. (2000) Editor's introduction: Birds and agriculture. J Appl Ecol 37:699-705.

Pacini, C., Wossink, A., Giesen, G. and Huirne, R. (2004) Ecological-economic modelling to support multi-objective policy making: a farming systems approach implemented for Tuscany. Agric Ecosyst Environ 102:349-364.

Perrings, C.P., Jackson, L., Bawa, K.S.,Brussaard, L., Brush, S.,Gavin, T., Papa, R., Pascual, U., and de Ruttier., P., 2006. Biodiversity in agricultural landscapes: saving natural capital without losing interest. Conserv Biol 20:263264.

Polasky, S., Nelson, E., Lonsdorf, E., Fackler, P. and Starfield, A. (2003) Conserving species in a working landscape: land use with biological and economic objectives. Ecological Applications 15:1387-1401.

Quaas, M.F., Baumgartner, S., Becker, C., Frank, K. and Mller, B. (2007) Uncertainty and sustainability in the management if rangelands. Ecol Econ 62:251-266.

Rashford, B.S., Dugger, B. and Adams, R.M. (2008) Application of a bioeconomic production model to improve wildlife management. J Wildl Manage 72:510-517.

Robinson, R.A., Wilson, J.D. and Crick, H.Q.P. (2001) The importance of arable habitat for farmland birds in grassland landscapes. J Appl Ecol 38:10591069.

Schlapfer, F., Schmid, B. and Seidl, I. (1999) Expert estmitates about effects of biodiversity on ecosystem processes and services. Oikos 84:346-352.

Schlapfer, F., Tucker, M. and Seidl, I. (2002) Returns from hay cultivation in fertilized low diversity and non-fertilized diversity grassland. Environmental and Resource Economics 21:89-100.

Sekercioglu, C., Daily, G.C. and Ehrlich, P. (2004) Ecosystem consequences of bird declines. PNAS 101:18042-18047.

Shi, T. and Gill, R. (2005) Developing effective policies for the sustainable development of ecological agriculture in China: the case study of Jinshan County with a systems dynamics model. Ecol Econ 53:223-246.

Swihart, R.K., Moore and Jeffrey E. (2003) Conserving Biodiversity in Agricultural Landscapes Model-Based Planning Tools. Purdue University press.

Tilman, D., Cassman, K.G., Matson, P.A., Naylor, R. and Polasky, S. (2002) Agricultural sustainability and intensive production practices. Nature 418:671677.

Van Wenum, J.H., Wossink, G.A.A. and Renkema, J.A. (2004) Locationspecific modelling for optimizing wildlife management on crop farms. Ecol Econ 48:395-407.

Vickery, J.A., Bradbury, R.B., Henderson, I.G., Eaton, M.A., Grice, P.V. (2004) The role of agri-environment schemes and farm management practices in reversing the decline of farmland birds in England. Biol Conserv 119:19-39. 
Widly, A. and Thomas, M.B. (2002) Natural enemy diversity and pest control: patterns of pest emergence with agricultural intensification. Ecol Lett 5:353-360.

Wretenberg, J., Lindstrom, A., Svenssen, S., Part, T. (2007) Linking agricultural policies to population trends of Swedish farmlands birds in different agricultural regions. J Appl Ecol 44:933-941.

Yachi, S. and Loreau, M (1999) Biodiversity and ecosystem productivity in a fluctuating environment: The insurance hypothesis. Proceedings of the National Academy of Sciences USA 96: 1463-1468. 


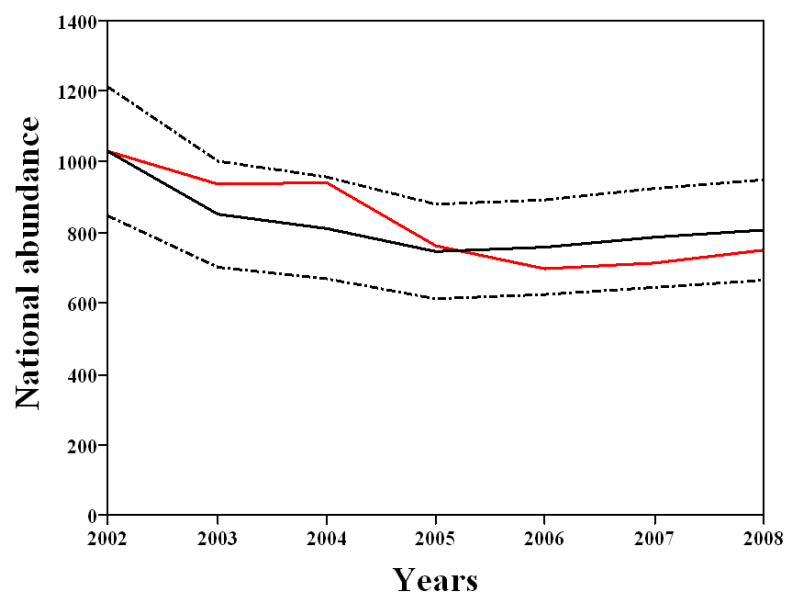

(a) The Stonechat Saxicola torquatus

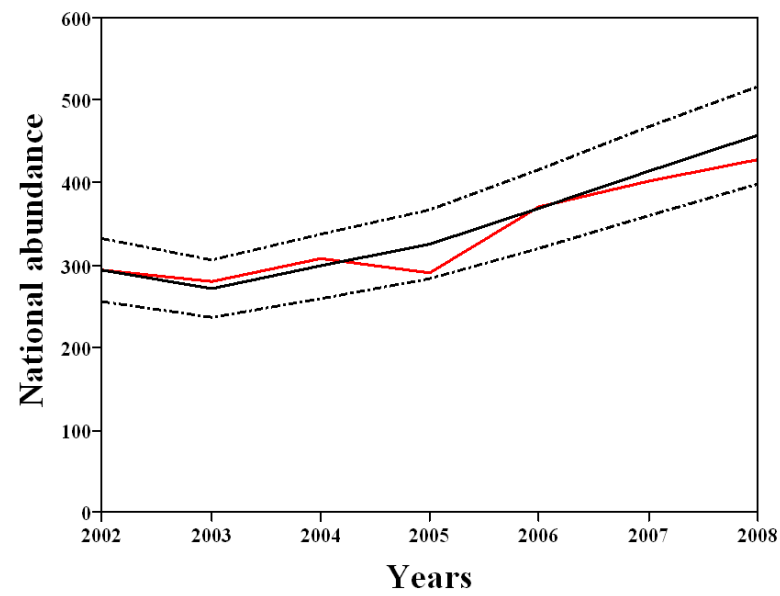

(b) The Red-backed Shrike Lanius collurio

Figure 1: Comparison between historical $\mathrm{N}_{\mathrm{s}, \mathrm{r}}(\mathrm{t})$ (red) and estimated $\widehat{\mathrm{N}}_{\mathrm{s}, \mathrm{r}}(\mathrm{t})$ (black) national abundances with the least square standard errors of calibration (dashed lines) for two of the species considered, the Stonechat Saxicola torquatus and the Red-backed Shrike Lanius collurio. 


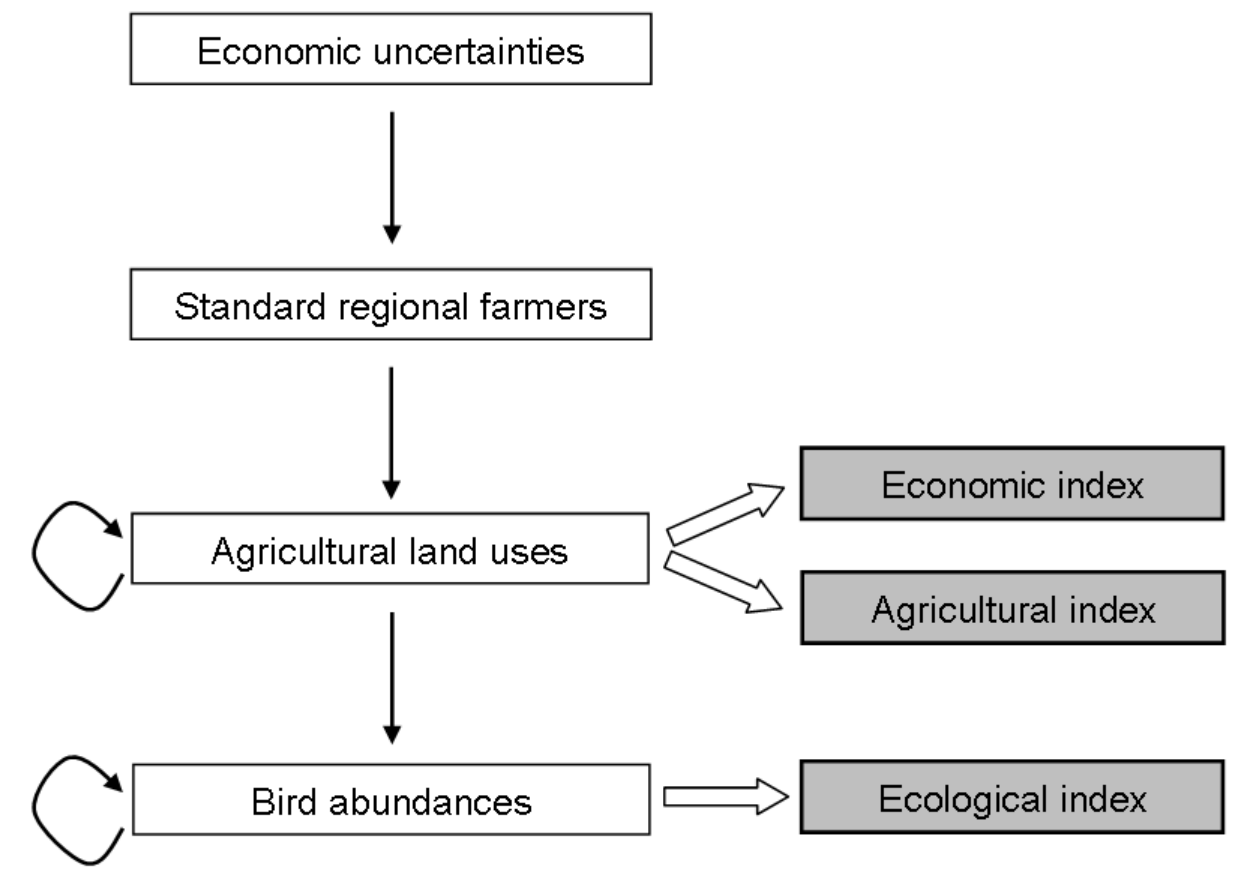

Figure 2: Model coupling: Farmers maximize their utility function and adjust their land uses depending on economic uncertainty and their risk aversion. These choices affect bird community dynamics. 


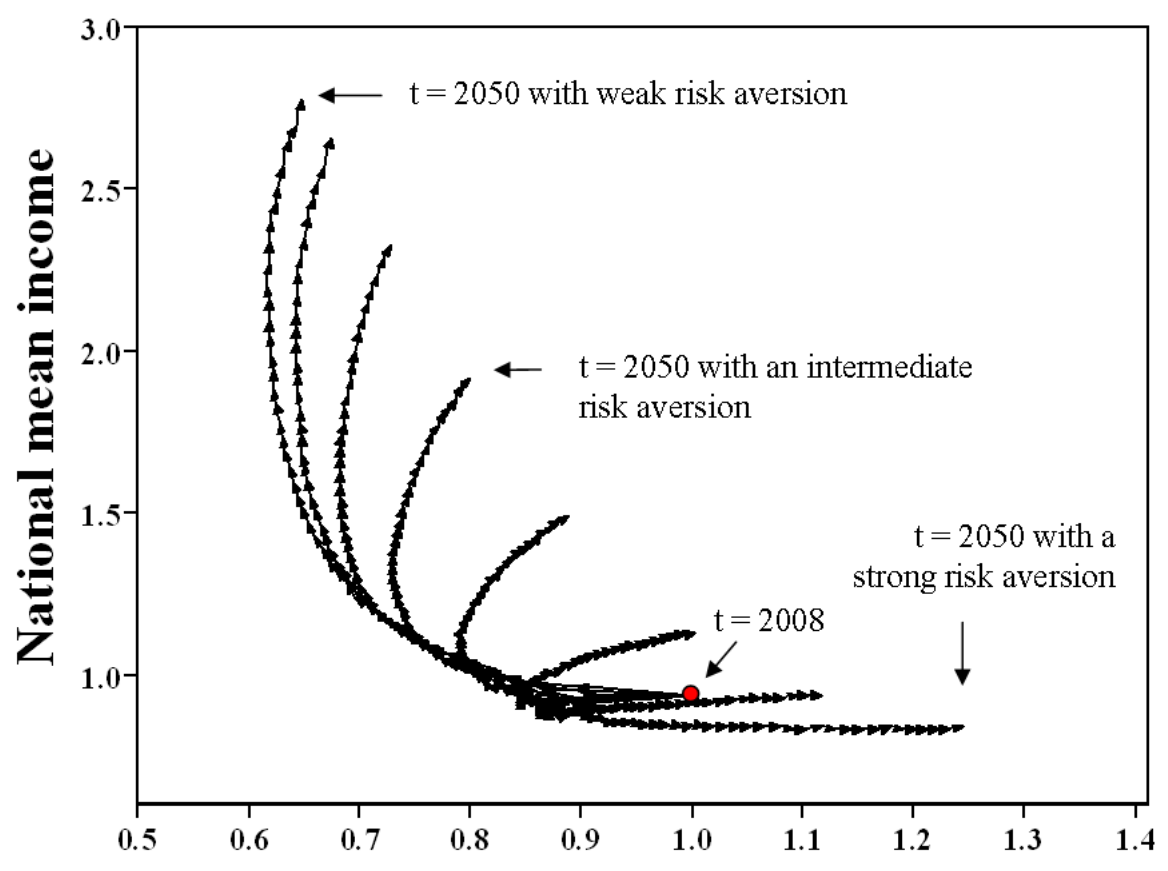

Farmland bird indicator

Figure 3: Mean bio-economic performances between $\overline{\operatorname{Inc}}_{\text {nat }}(t)$ and $\mathrm{FBI}_{\text {nat }}(t)$ in a context of economic uncertainty for different levels of risk aversion. All trajectories start at the same red point : $t=2008$. 


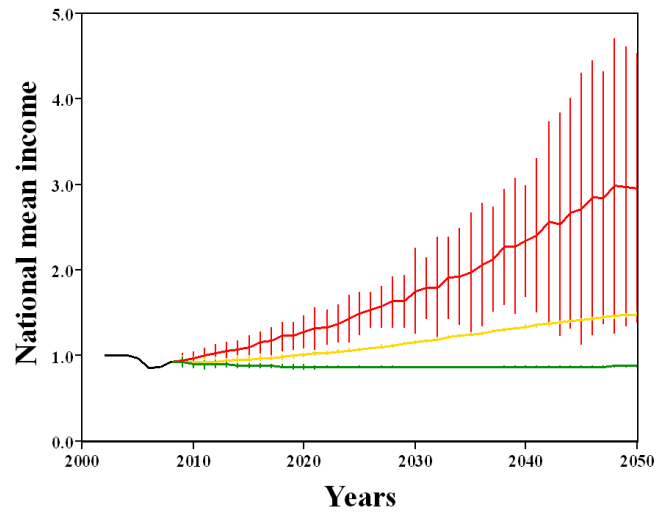

(a) National mean income trends $\overline{\operatorname{Inc}}_{\text {nat }}(t)$

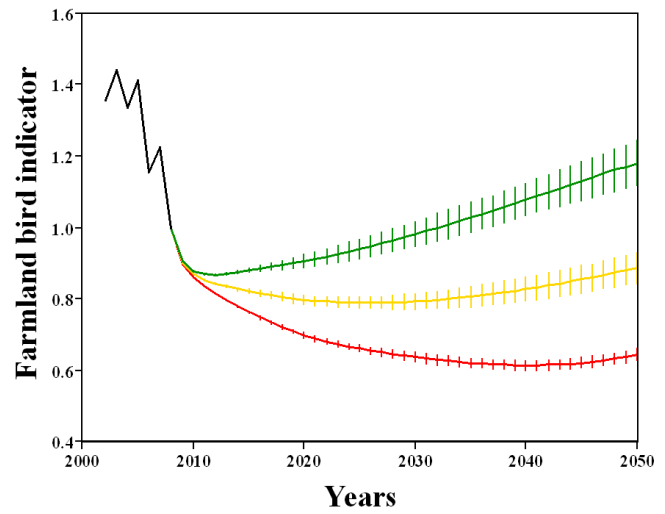

(b) Farmland bird indicator trends $\mathrm{FBI}_{\text {nat }}(t)$

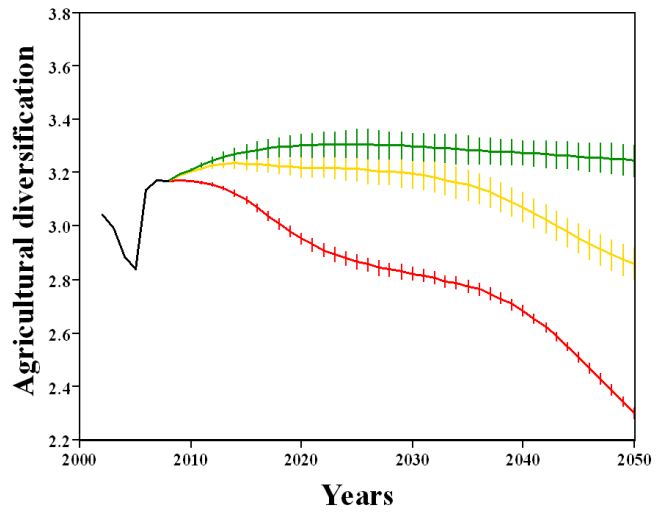

(c) Agricultural diversification trends $\operatorname{Hdiv}_{\text {nat }}(t)$

Figure 4: Bio-economic performances and agricultural diversification for three contrasted risk aversion levels with $95 \%$ confidence interval (red: weak risk aversion, yellow: intermediate risk aversion, green: strong risk aversion, black: historical data). 


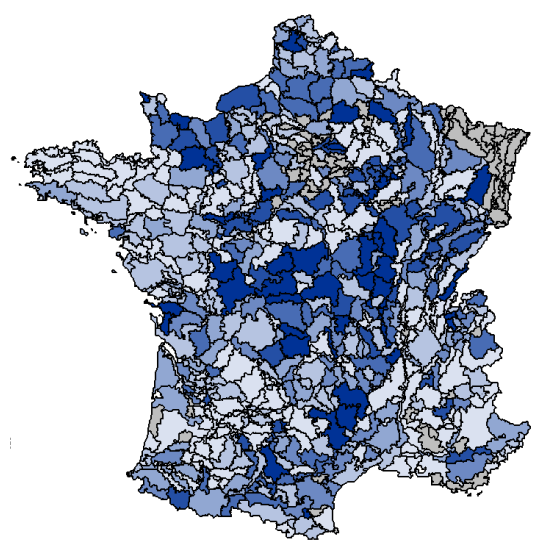

(b) 2050 with a low risk aversion

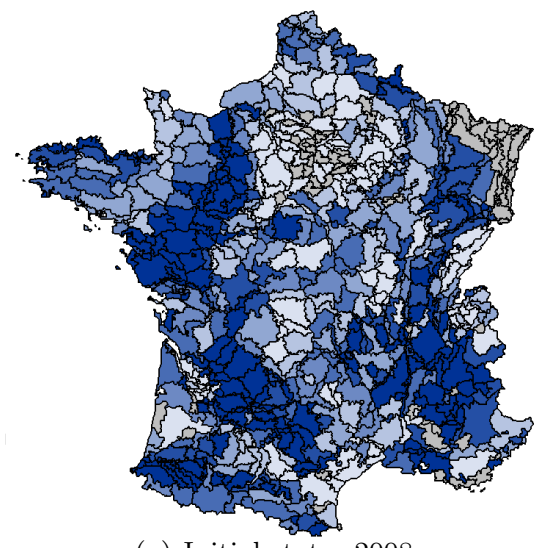

(a) Initial state: 2008

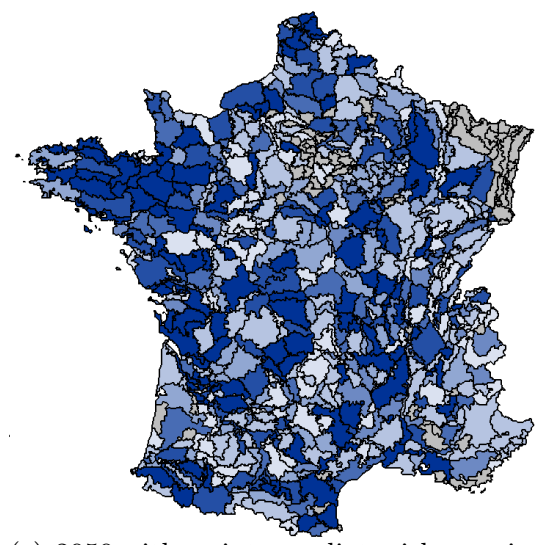

(c) 2050 with an intermediate risk aversion

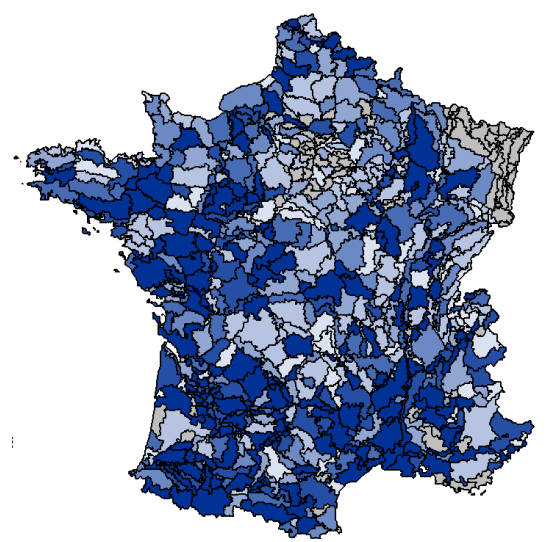

(d) 2050 with a strong risk aversion

Figure 5: Comparison of agricultural diversification at the PRA scale $\operatorname{Hdiv}_{r}(t)$ in 2008 and in 2050 according to the risk aversion level (dark blue: strong diversity, pale blue: weak diversity, gray: NA). 


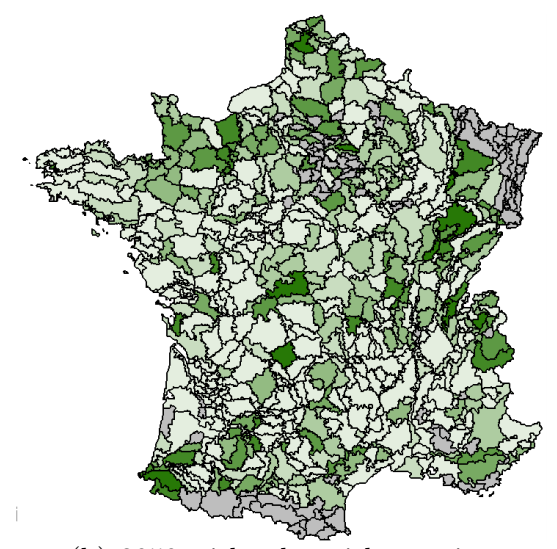

(b) 2050 with a low risk aversion

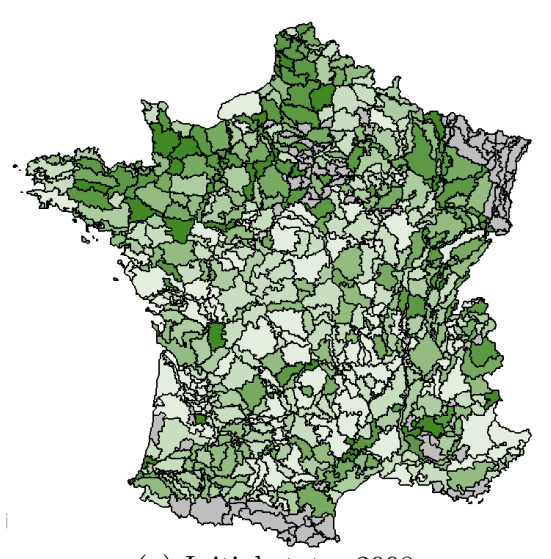

(a) Initial state: 2008

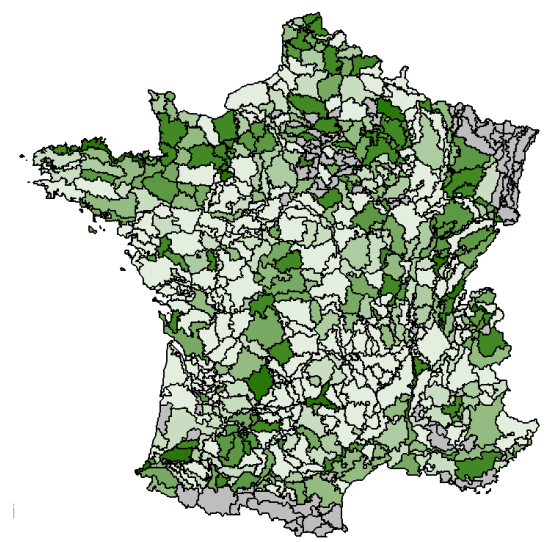

(c) 2050 with an intermediate risk aversion

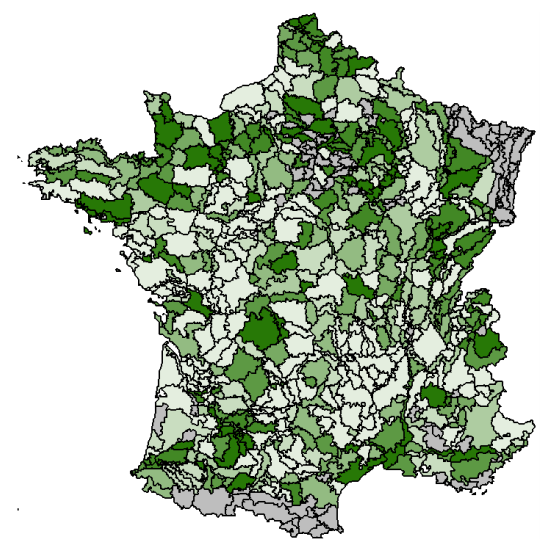

(d) 2050 with a strong risk aversion

Figure 6: Comparison of Farmland Bird Index at the PRA scale $\mathrm{FBI}_{r}(t)$ in 2008 and in 2050 according to the risk aversion level (dark green: strong FBI, pale green: weak FBI, gray: NA). 


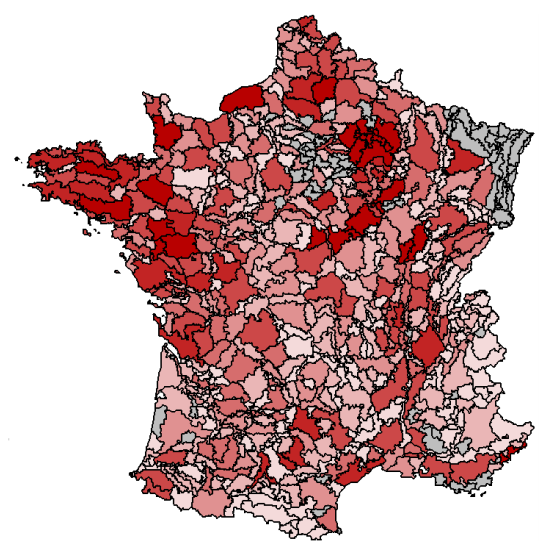

(b) 2050 with a low risk aversion

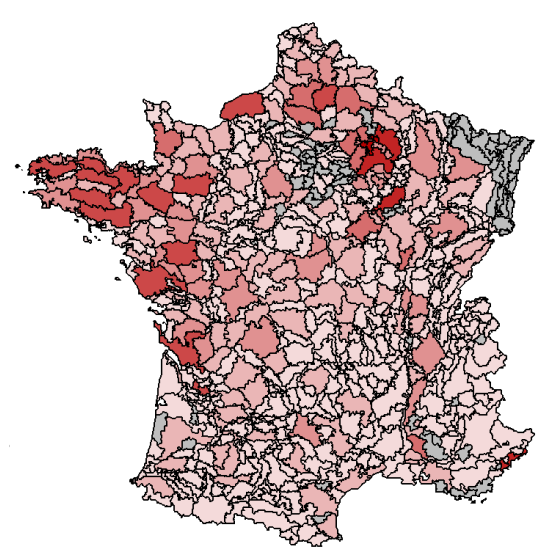

(a) Initial state: 2008

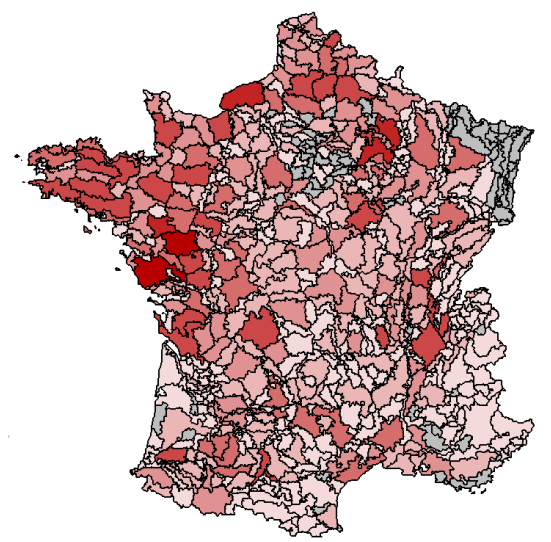

(c) 2050 with an intermediate risk aversion

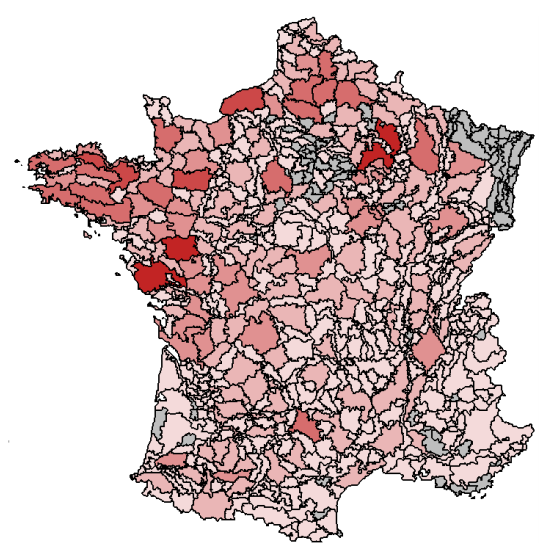

(d) 2050 with a strong risk aversion

Figure 7: Comparison of income at the PRA scale $\operatorname{Inc}_{r}(t)$ in 2008 and in 2050 according to the risk aversion level (dark red: strong income, pale red: weak income, gray: NA). 


\title{
Cahiers du GREThA Working papers of GREThA
}

\author{
GREThA UMR CNRS 5113 \\ Université Montesquieu Bordeaux IV \\ Avenue Léon Duguit \\ 33608 PESSAC - FRANCE \\ Tel : +33 (0)5.56.84.25.75 \\ Fax : +33 (0)5.56.84.86.47 \\ http://gretha.u-bordeaux4.fr/
}

\section{Cahiers du GREThA (derniers numéros - last issues)}

2011-29 : MABROUK Fatma, Migration de retour, de la théorie à la pratique

2011-30 : MOYES Patrick, GRAVEL Nicolas, Utilitarianism or Welfarism: Does it Make a Difference?

2011-31 : BROUILLAT Eric, Durability of consumption goods and market competition: an agentbased modelling

2011-32 : BONIN Hubert, En quête des étapes de renouveau de l'esprit d'entreprise français dans les années 1950-2000

2011-33 : MONTALBAN Matthieu, RAMIREZ-PEREZ Sigfrido, SMITH Andy, EU Competition Policy Revisited: Economic Doctrines Within European Political Work

2011-34 : FRIGANT Vincent, Three uncertainties looming over the European auto industry

2011-35 : MOYES Patrick, Rearrangements and Sequential Rank Order Dominance. A Result with Economic Applications

2011-36 : MOYES Patrick, GRAVEL Nicolas, Ethically Robust Comparisons of Bidimensional Distributions with an Ordinal Attribute

2011-37 : LEE Ji-Yong, Crises et transformation des modèles de gouvernance d'entreprise en Asie

2011-38: CISSE Abdoul, GOURGUET Sophie, DOYEN Luc, BLANCHARD Fabian, PEREAU JeanChristophe, A bio-economic model for the ecosystem-based management of the coastal fishery in French Guiana

2011-39 GABILLON Emmanuelle, One Theory For Two Risk Premia

2012-01 : NICET-CHENAF Dalila, Model of Financial Development: a cluster analysis

2012-02 : MOYES Patrick, MAGDALOU Brice, The Absence of Deprivation as a Measure of Social Well-Being. An Empirical Investigation

2012-03 : MOUYSSET Lauriane, DOYEN Luc, JIGUET Frédéric, How does the economic risk aversion affect biodiversity?

La coordination scientifique des Cahiers du GREThA est assurée par Sylvie FERRARI et Vincent FRIGANT. La mise en page est assurée par Anne-Laure MERLETTE. 